\title{
Saying too Little and Saying too Much. Critical notice of Lying, Misleading, and What is Said, by Jennifer Saul
}

\author{
Andreas Stokke \\ Umeå University
}

BIBLID [0873-626X (2013) 35; pp. 81-91]

\section{Introduction}

You are going to Paul's party tonight. You have a long day of work ahead of you before that, but you can't wait to get there. Your annoying friend comes up to you and says, 'Hi! Oh, are you going to Paul's party tonight? I don't think I'll go. Unless your going?' You reply, 'I have to work.'

There are lies and then there are misleading utterances that are not lies. You did not lie to your friend, although you were being misleading. This difference has been the center of much attention mainly in two areas of philosophy. First, there have been attempts from within philosophy of language to characterize the difference between lies and merely misleading utterances qua speech acts. ${ }^{1}$ Second, there is a longstanding debate over the moral significance of the difference, and in particular over to what extent lying is always morally worse than merely misleading. ${ }^{2}$

So there are mainly two questions that philosophers have been interested in regarding the lying-misleading distinction, namely

\footnotetext{
${ }^{1}$ See, e.g., Carson (2005), Sorensen (2007), Fallis (2009), Stokke (forthcoming).

2 See, e.g., Kupfer (1982), Korsgaard (1986), MacIntyre (1995), Adler (1997), Williams (2002), Mahon (2003), (2006), (2009).

Disputatio, Vol. V, No. 35, May 2013
}

Received: 11/05/2013. Accepted: 11/05/2013 
(i) What speech act is required for lying (vs. merely misleading)?

(ii) What is the moral difference between lying and merely misleading?

Jennifer Saul's recently published book, Lying, Misleading, and What is Said. An Exploration in Philosophy of Language and Ethics, proposes answers to both these questions, and as such makes a contribution to both spheres of interest concerning the lying-misleading distinction.

Saul's answer to the first question is that lying requires saying, understood in a certain way. Her answer to the second question is that there is no moral difference between lying and merely misleading.

\section{Saul on saying}

The idea that, from a linguistic point of view, the difference between lying and merely misleading turns on a difference between ways of conveying information, i.e., a difference in the speech acts involved in each, is a widespread one. It is easy to appreciate why. Speakers have attitudes toward information they convey. Typically speakers believe, or even know, what they convey, but sometimes a speaker conveys information she believes, or even knows, to be false. There are many ways of conveying information. Some are such that if the speaker believes that the relevant information is false, she is lying. But there are others for which believing the information to be false does not qualify as lying, although the utterance will be a misleading one.

What mode of communication is required for lying? Intuitively, saying is a good candidate. You did not say that you are not going to Paul's party. You implicated that. It is natural to explain how you managed to avoid lying, while still succeeding in misleading your annoying friend, by pointing to the fact that while you did indeed convey information you believed to be false, you did not do so by saying it.

So it is plausible to think that, roughly, lying requires saying something, and that one way of refraining from lying while succeeding in misleading is to convey information one believes to be false while avoiding saying it.

Saul's project in the first part of the book is to carve out a no- 
tion of saying that will delineate the lying-misleading distinction correctly in general. The strategy that she takes up in pursuing this task is a novel one. Saul's approach is to turn to the debates over what is said familiar from philosophy of language at large - and in particular from the disputes over the semantics-pragmatics distinction. Saul's book is, to my knowledge, the first work that takes on the task of answering question (i) from a standpoint wholly informed by these contemporary debates in philosophy of language.

Saul stresses that finding a notion of saying that will capture the lying-misleading distinction is not necessarily a contribution to the debate in philosophy of language more generally concerning the notion of what is said. Rather, her project is to consider a range of proposals from these debates and attempt to recover a characterization of saying that will correctly delineate the lying-misleading distinction. Yet it may be that the notion that is under dispute in the semantics-pragmatics literature is a different one.

Here I shall not go through Saul's discussion of the complexity of the extensive literature on what is said. Rather, I shall confine myself to commenting on her final suggestion. For the purpose of capturing the distinction between lying and merely misleading, Saul proposes to characterize saying as follows:

(NTE) A putative contextual contribution to what is said is a part of what is said only if without this contextually supplied material, $\mathrm{S}$ would not have a truth-evaluable semantic content in $\mathrm{C}$.

This principle has been discussed by writers on the semantics-pragmatics distinction. For example, Recanati (1993: 242) calls it the 'Minimal truth-evaluability principle.'

Familiarly, these debates chiefly concern phenomena such as what is often called 'expansion' and 'completion. ${ }^{.4}$ And as such, these are the kinds of phenomena that Saul discusses with respect to the lyingmisleading distinction. Here is one of her examples:

Dave is lying in bed, and two nurses are discussing the treatment he needs. Ed holds up a bottle of heart medicine, points at it, and utters (1):

\footnotetext{
${ }^{3}$ See also Bach (1994: 160-161).

${ }^{4}$ This is the terminology of Bach (1994).
} 
(1) Has Dave had enough?

Fred replies with (2):

(2) Dave's had enough.

As it turns out, Fred hates Dave, wants him to die, and plans to bring this about by denying him his much-needed heart medicine. ${ }^{5}$

As Saul notes, Fred's reply is intuitively a lie. And it is clear that, together with the claim that lying requires saying, (NTE) captures this. For Fred's utterance to be truth-evaluable, it requires completion. In this context the salient completion is the one illustrated in (3).

(3) Dave's had enough heart medicine.

So, according to (NTE), Fred counts as having said (3), and hence this explains why his utterance is a lie.

However, Saul's proposal can nevertheless be seen to undergenerate. There are cases in which someone lies as a result of conveying information they believe to be false, but where that information is not required for the truth-evaluability of their utterance. Consider, for instance, the following situation:

Jasper's neighborhood recently put on a Community Week. People helped their neighbors out with various chores and tasks that needed doing. Selfishly, however, Jasper used Community Week to fix the roof on his own house, ignoring the neighbors. The following week Jasper is having dinner with Doris. Jasper is keen to give Doris a good impression of himself.

(4) Doris. So how did you help out during Community Week? Jasper. I fixed a roof.

Jasper's reply is a lie. So, it is natural to think that, on Saul's view, there must be a piece of information that he says while believing that it is false. There are two candidates, (4a) and (4b). 
(4a) The roof Jasper fixed was not his own. ${ }^{6}$

(4b) Jasper helped out during Community Week by fixing a (someone else's) roof.

Both (4a) and (4b) are propositions that Jasper believes to be false. But neither counts as said, given the Minimal truth-evaluability principle, i.e., (NTE). Jasper's utterance is truth-evaluable without supplementation. It is true if and only if he fixed a roof.

Here is Saul's full definition of lying:

Lying (Complete):

If the speaker is not the victim of error/malapropism or using metaphor, hyperbole, or irony, then they lie iff (A) or (B) holds:

(A) (1) They say that P; (2) They believe P to be false; (3) They take themself to be in a warranting context.

(B) (1) They say something indeterminate across a range of acceptable propositions in the range $\mathrm{CP} 1 \ldots \mathrm{CPn}$; (2) for each complete proposition in the range $\mathrm{CP} 1 \ldots \mathrm{CPn}$, they believe that proposition to be false; (3) They take themself to be in a warranting context. ${ }^{7}$

Is the problem raised above avoided by the full Lying (Complete)? No. Both (A) and (B) are false for Jasper's reply in (4). He does not say either (4a) or (4b), according to (NTE). So (A) is false. And his utterance is not indeterminate across a range of completions. It is not in need of completion at all. So (B) is false. Hence, since Jasper is lying, his reply is a counterexample to the left to right direction of Lying (Complete).

Further, there are cases of merely misleading that present challenges for Saul's view. For example, consider Larry's utterance in the following scenario:

Larry is keen on making himself seem attractive to Alice. He knows she's interested in logic - a subject he himself knows very little about. From talking to her he has become aware that she is under the mistaken impression that he has just finished writing a

${ }^{6}$ On some views, e.g., that of Grice (1989), this information is a generalized implicature of Jasper's utterance.

${ }^{7}$ Saul (2012: 65). 
book. Larry has indeed been walking around with a manuscript for a book about logic. And he knows Alice has seen him with it. However, it's not a manuscript for a book he wrote himself, but rather one that he has been assigned to design a cover for by the publisher he works for.

(5) Alice. Do you know a lot about logic? Larry. My book is about logic.

While Larry is not lying in this case, he is clearly being misleading. So it is natural to think that, on Saul's view, there should be a piece of information that Larry conveys and which he believes to be false, but which is not said. There are two candidates, (5a) and (5b).

(5a) Larry knows a lot about logic.

(5b) The book Larry wrote is about logic.

(5a) is clearly not said by Larry's utterance. So the more interesting candidate is (5b). However, at least at first blush, (5b) is not precluded from counting as said, given the Minimal truth-evaluability principle. (5b) is clearly a putative contribution to what is said, and Larry's utterance is not truth-evaluable without a contextually specified relation between him and the book.

Does Lying (Complete) avoid this problem? One possibility here is to argue that Larry's reply is indeterminate across a range of acceptable completed propositions, and that among them is (5c).

(5c)The book Larry has been assigned to design a cover for is about logic.

(5c) is something Larry believes to be true. Hence, if this is right, (B) is false in this case.

However, for the problem to be alleviated, (A) would also need to be false. Is it? I suggested above that it is not, because the proposition that is most plausibly taken to be said by his utterance, namely (5b), indeed does have this status since the completion is required for truth-evaluability. On the other hand, if we agree that Larry's utterance is indeterminate across a range of propositions, this argument 
does not hold up. Saul explicitly claims that in such cases, 'what is said is indeterminate across a range of precise propositions. ${ }^{8}$ Hence, in such cases (A) is also false (or at least not true), since (A1) is false (or at least not true.)

I think this suggestion about Larry's reply should be rejected. The reason is that if Larry's utterance is indeterminate across a range of acceptable completions, it is hard to see how his utterance could be misleading. Clearly, the reason Larry is being misleading is because he intends to make Alice believe (5b), and as a result (5a). Indeed, Alice will take him to be conveying both. So, as we said earlier, (5b) is certainly a putative contribution to what is said. Hence, (NTE) would seem to predict that Larry says (5b). Even though, to be sure, (NTE) is only a necessary condition on saying, it is hard to see how to avoid this result. Yet this prevents the account from agreeing that Larry is not lying.

What we want to say about the case is that Larry's utterance is misleading because it conveys (5b), which is something that he believes to be false, but that he is not lying because he does not convey (5b) by saying it. However, this verdict is not easily available to Saul's account. Since (B) is of no help, this view at the very least must find a way of explaining why (5b) is not said, given the Minimal truthevaluability principle. Hence, I think that, since Larry is not lying, the case is at least an explanatory challenge for the right to left direction of Lying (Complete).

\section{Saul on the moral significance of the lying-misleading distinction}

The second aim of the book is to argue for a complex picture of the moral significance of the lying-misleading distinction. Saul's main claim is that, contrary to one long tradition in philosophy, lying and merely misleading are morally on a par. As she says, "As far as the acts go, misleading is not morally better than lying.'

The rider ('As far as the acts go') is important. Saul complicates

\footnotetext{
${ }^{8}$ Saul (2012: 64).

${ }^{9}$ Saul (2012: 86).
} 
her picture by arguing that, even though lying and merely misleading are morally equivalent, 'decisions about lying and misleading may be genuinely (not just apparently) morally revealing about the character of the actor. ${ }^{10}$ So, Saul simultaneously endorses the following two claims:

(A) There is no moral difference between lying and merely misleading.

(B) The choice between lying and merely misleading may be genuinely morally revealing about the character of the actor.

Saul's argument for (A) relies on cases like this one:

George makes dinner for Frieda. He knows that Frieda has a peanut allergy so virulent that even a small amount of peanut oil could kill her. He wants to kill Frieda, so he has cooked with peanut oil. Frieda, being rightly cautious, asks whether George has put any peanuts in the meal. George utters the true but misleading (6) rather than the false (7).

(6) No, I didn't put any peanuts in.

(7) No, it's perfectly safe for you to eat. ${ }^{11}$

Saul writes,

it doesn't seem likely to me that anyone would think this choice of George's makes his act even slightly better. ${ }^{12}$

I think some will take issue with this claim. For example, if one believes in the existence of a duty not to lie, one might maintain that (7) would indeed be morally worse, even though it is on a par with (6) as far as consequences go.

However, here I want to comment on a different point. Namely, the fact that Saul's position endorses both (A) and (B). There is a tension between (A) and (B), as Saul is well aware. As she observes,

Some choices tend to be revealing about people's moral characters. In general, these are choices between options where one is morally better

\footnotetext{
${ }^{10}$ Ibid.

${ }^{11}$ Saul (2012: 73). Example numbering altered.

${ }^{12}$ Ibid.
} 
than the other. ${ }^{13}$

But Saul nevertheless maintains that

What's interesting about the case of choices between lying and misleading is that it seems plausible to suppose that such choices will often be morally revealing; and yet, if I am right, one is not morally better than the other. ${ }^{14}$

The challenge is, then, to explain how (B) can be true, given the truth of (A).

As Saul notes, it is important to point out a caveat up front. Namely that if someone believes that there is a moral difference between lying and merely misleading, it is not surprising that her choices in this area may be revealing about her moral character. But to vindicate her position, Saul needs to argue for the further claim that, even choices concerning lying vs. merely misleading made by people who consciously believe (A) may be revealing about their moral character.

Saul provides some ways in which this can be true in particular cases. On the one hand, the agent's choice may be based on a desire for deniability, in which case the choice may be negatively revealing about her character. On the other hand, the choice may be based on other factors. As examples, Saul mentions hypocrisy, epistemic hedging of bets (as a result of not being certain of being right), or a self-deceived desire to avoid guilt. And there may be others. In cases involving such further factors, again, it is not surprising that the agent's choice between lying and merely misleading may be morally revealing about them.

If Saul is right, there should be no cases in which a choice by someone who believes (A) is genuinely morally revealing about her unless the choice is based on factors like the ones Saul mentions. It is clear that if (A) is true, this follows. But moreover, the endorsement of (A) also implies that judgments about the relative badness or goodness of a choice between lying vs. merely misleading are always mistaken.

Such judgments abound. We make them routinely. But they are all in error, on Saul's view. This seems like a relatively high cost for

\footnotetext{
${ }^{13}$ Saul (2012: 91).

${ }^{14}$ Ibid.
} 
the view. One might try to argue that, at least in many cases, the judgments are not erroneous because their subject matter is different from what it seems to be. Perhaps the judgments are often, or even typically, really about the moral character of the agent. But this is just to introduce error at a higher level, since it seems clear that at least most people who make such judgments believe that they are about what they seem to be about.

Suppose that Mark consciously makes a judgment to the effect than an act of lying was morally worse than an available alternative to merely mislead. Mark himself thinks the judgment is about what it seems to be about, i.e., the moral difference between the two choices. According to the present proposal, however, either Mark is mistaken about this, and the judgment is really about something else (in which case the judgment may in turn be either correct or mistaken about its real subject matter), or Mark is right, but the judgment is mistaken, since there really is no moral difference. So the only way that Mark's judgment can be right, according to this suggestion, is if Mark is mistaken about what its subject matter is. Hence, he could never think he is right and be so. This is surely an even higher cost.

But even if Saul sticks to the simpler view - that all judgments about moral differences between lying and merely misleading indeed have such differences as their subject matter, and hence they are all in error - some might be tempted to conclude that someone who rejects (A) has a more attractive position to offer. This theorist has a plausible way of accounting for (B). She will say that choices between lying and merely misleading can be morally revealing about the character of a person making such a choice simply because one option is morally better than the other. Further, the theorist who rejects (A) has an easy time explaining why judgements about the moral difference between lying and merely misleading are so common, and she has a straightforward picture of their subject matter.

To be sure, the traditional theorist must explain why, as Saul's arguments bring out, the feeling of the moral preference for misleading is weakened in cases like the one involving George, Frieda, and the peanuts. Yet it may seem plausible that an explanation, which points to the severity of the stakes involved, can be given.

Despite these comments, Saul's book is a welcome and challenging contribution to the debates over the lying-misleading distinction. 
It presents a novel way of construing the distinction both from the point of view of philosophy of language and ethics. Saul advances the discussion by integrating contemporary research from the semantics-pragmatics debate, and she makes a strong case for rejecting traditional views on the moral preference for misleading over lying. Lying, Misleading, and What is Said should be read by everyone with an interest in this area.

Andreas Stokke Department of Philosophy Umeå University andreas.stokke@umu.se

\section{References}

Adler, J. 1997. Lying, deceiving, or falsely implicating. Journal of Philosophy, 94: $435-452$.

Bach, K. 1994. Conversational impliciture. Mind and Language, 9: 124-162.

Carson, T. 2006. The definition of lying. Noûs, 40: 284-306.

Fallis, D. 2009. What is lying? Journal of Philosophy, 106: 29-56.

Grice, H. 1989. Studies in the way of words. Harvard University Press.

Korsgaard, C. 1986. The right to lie: Kant on dealing with evil. Philosophy and Public Affairs, 15: 325-349.

Kupfer, J. 1982. The moral presumption against lying. Review of Metaphysics, 36: $103-126$

MacIntyre, A. 1995. Truthfulness, lies, and moral philosophers: What can we learn from Mill and Kant? The Tanner Lectures on Human Values, 16: 307-361.

Mahon, J. 2003. Kant on lies, candour and reticence. Kantian Review, 7: 102-133.

Mahon, J. 2006. Kant and the perfect duty to others not to lie. British Journal for the History of Philosophy, 14: 653-685.

Mahon, J. 2009. The truth about Kant on lies. In The philosophy of deception, ed. by Martin, C. pages 201-224. Oxford University Press.

Recanati, F. 1993. Direct reference - from language to thought. Blackwell.

Saul, J. 2012. Lying, misleading, and the role of what is said. An exploration in philosophy of language and ethics. Oxford University Press.

Sorensen, R. 2007. Bald-faced lies! Lying without the intent to deceive. Pacific Philosophical Quarterly, 88: 251-264.

Stokke, A. (forthcoming). Lying and asserting. Forthcoming in Journal of Philosophy.

Williams, B. 2002. Truth and truthfulness: An essay in genealogy. Princeton University Press. 